\title{
Article
}

\section{High vegetables intake and response to COPD rehabilitation. The role of oxidative stress, inflammation and DNA damage}

\author{
Sara Ilari ${ }^{1}$, Laura Vitiello ${ }^{2}$, Patrizia Russo ${ }^{3,4}$, Stefania Proietti ${ }^{3}$, Mirta Milić $^{5}$, Carolina Muscoli ${ }^{1}$, Vittorio Cardaci ${ }^{6}$, \\ Carlo Tomino ${ }^{7}$, Gaia Bonassi ${ }^{8}$, and Stefano Bonassi ${ }^{3,4}$.
}

1 Department of Health Science, Institute of Research for Food Safety \& Health (IRC-FSH), University "Magna Graecia" of Catanzaro, 88201 Catanzaro, Italy.

2 Laboratory of Flow Cytometry, IRCCS San Raffaele Roma, Rome, Italy

3 Clinical and Molecular Epidemiology, IRCCS San Raffaele Roma, Rome, Italy

4 Department of Human Sciences and Quality of Life Promotion, San Raffaele University, Rome, Italy.

5 Institute for Medical Research and Occupational Health, Mutagenesis Unit, Zagreb, Croatia.

6 Pulmonary Rehabilitation Unit, IRCCS San Raffaele Roma, Rome, Italy.

7 Scientific Direction, IRCCS San Raffaele Roma, 00166 Rome, Italy.

8 S.C. Medicina Fisica e Riabilitazione Ospedaliera, ASL4, Azienda Sanitaria Locale Chiavarese, Italy

* Correspondence: patrizia.russo@sanraffaele.it; Tel.: +390652253409

\begin{abstract}
Chronic obstructive pulmonary disease (COPD) is a respiratory disease associated with airways inflammation and lung parenchyma fibrosis. The primary goals of COPD treatment are to reduce symptoms and risk of exacerbations, therefore pulmonary rehabilitation is considered the key component of managing COPD patients. Oxidative airway damage, inflammation and reduction of endogenous antioxidant enzymes are known to play a crucial role in the pathogenesis of COPD. Natural antioxidants have also recently been considered as they play an important role in metabolism, DNA repair and fighting the effects of oxidative stress. In this paper we evaluated the response of 105 elderly COPD patients to pulmonary rehabilitation (PR), based on high or low vegetable consumption, by analyzing clinical parameters and biological measurements at baseline and after completion of the three weeks PR. We found that high vegetable intake in normal diet, without any specific intervention, can increase the probability to successfully respond to rehabilitation $(65.4 \%$ of responders ate vegetables daily $v s .40 .0 \%$ of Non-Responders, $\mathrm{p}=0.033)$. Three weeks of pulmonary rehabilitation are probably too short to reveal a reduction of the oxidative stress and DNA damage, but are enough to show an improvement in the patient's inflammatory state.
\end{abstract}

Keywords: Chronic obstructive pulmonary disease (COPD); Pulmonary Rehabilitation; Vegetables; DNA damage; Genomic Instability; Oxidative stress; Inflammation.

\section{Introduction}

Chronic obstructive pulmonary disease (COPD) is characterized by airflow limitation associated with a chronic inflammatory response to noxious stimuli or gases[1,2] and is among the most common causes of mortality and disability in the world $[2,3]$. COPD is age-dependent and mortality is more common in women than in men [3]. Smoking is the primary risk factor for COPD, although, only $15 \%$ of smokers develop the disease [3]; infections and obesity also are considered triggering conditions [1,2,4]. Oxidative stress and associated inflammation play a key role in the pathogenesis of obstructive airway diseases. Specifically, inhaled particles and inflammatory mediators contribute to the development of reactive oxygen and nitrogen species (free radicals, ROS; RNS), resulting in oxidative stress, responsible for harmful effects, such as damage to lipids, proteins, and nucleic acids [1,2]. 
It has been observed that COPD patients, had an increase in markers of oxidative airway damage (related to DNA, proteins, and lipid) and a reduction of endogenous antioxidant enzymes [4,5], thus aggravating the oxidant/antioxidant unbalance [6]. Indeed, oxidative stress and the consequent oxidative damage, through the accumulation of lipid peroxidation products (Malondialdehyde (MDA)) and DNA oxidation (8hydroxy-2'-deoxyguanosine (8-OHdG)), is responsible for post-translational modification proteins (carbonylation, nitration), by altering mitochondrial regulation pathways in neurodegenerative and cardiovascular diseases, and chronic inflammation in COPD $[7,8]$. In addition, the higher oxidative burden associated with inflammatory processes, is accompanied by a continuous cycle of DNA damage and repair, leading to a higher rate of cell turnover, increasing the likelihood of genetic errors [9].

Inflammation, therefore, plays a pivotal role in the pathogenesis of COPD. The presence of chronic pulmonary disease leads to a degeneration of motor activity, caused by alterations in the function of skeletal and ventilator muscles [10,11], causing, in turn, an increase of ROS, leading to muscle damage and inflammation, thus generating a vicious circle of disabling symptoms [12]. Protease-antiprotease imbalance, and the higher number of pro-inflammatory cells (mainly neutrophils), are the main drivers of primarily non-infectious inflammation in COPD. The complex series of events that involves immune trigger cells, and activates innate and cell-mediated inflammatory responses, contribute to the irreversible airflow limitation, lung remodeling, and emphysema in these patients. COPD clinical features include persistent respiratory symptoms and only partially reversible airflow obstruction, due to an abnormal inflammatory response of the lungs to noxious particles and gases. Exacerbations of COPD, for example, are acute proinflammatory events $[13,14]$.

Pulmonary rehabilitation (PR) is considered the key component of the management of COPD patients [15]. A comprehensive intervention, which includes exercise training, education, and behavioral changes, is the most suitable approach to improve muscles endurance and strength and reduce symptoms of dyspnea [16]. A regular exercise program could be considered a good oxidative defense system, improving adaptive responses, promoting a more efficient oxidative metabolism, and/or increasing the activation of endogenous antioxidant systems [17]. ROS excess is inactivated by antioxidants (such as polyphenols) which inhibit molecule oxidation by removing free radicals [18]. Recently, the use of natural antioxidants in the treatment of COPD because of their protective role against oxidative stress has been described $[5,19]$. The intake of nutrients and micronutrients with antioxidant properties plays an important role in DNA metabolism and DNA repair, contributing to maintaining genome stability, and fighting the effects of the oxidative stress. Lower levels of DNA damage have been associated with lower levels of several inflammatory diseases severity and moderate exercise training (Figure 1) $[9,20,21]$. 


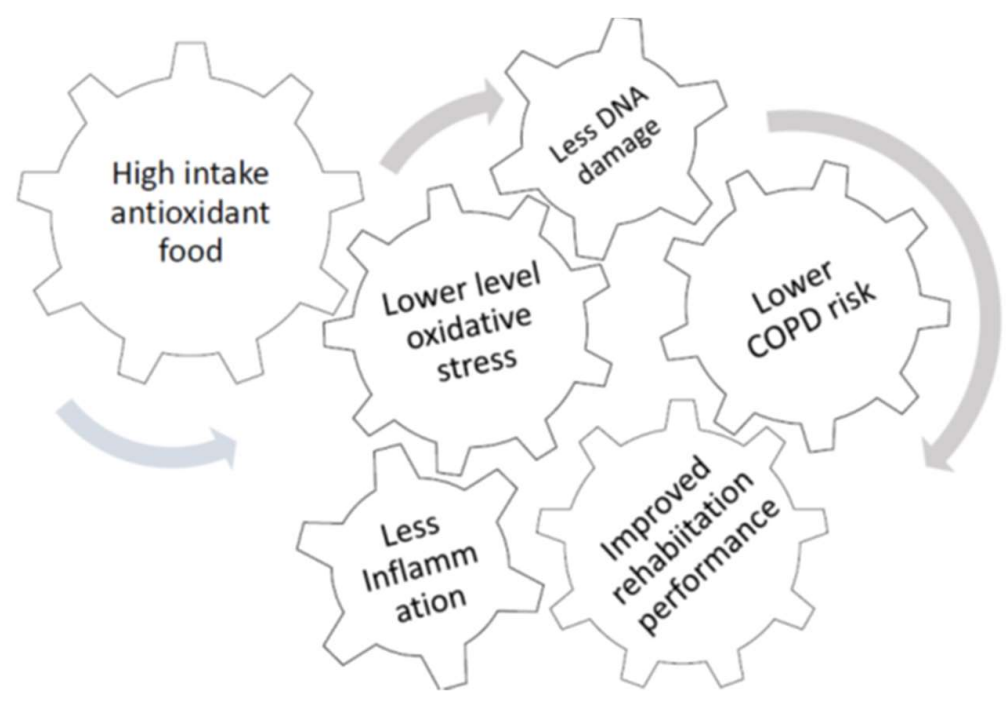

Figure 1: Complex machinery illustrating how a high consumption of food with antioxidant properties may be beneficial in reducing the level of oxidative stress and inflammation, but also improving genomic stability, reducing the risk of COPD, and improving physical performance.

High consumption of fruit and vegetables has been associated with a lower risk of lung diseases [22,23], is considered a key intervention for the prevention and treatment of cardiovascular diseases [24], and is associated with a lower risk of cancer and all-cause mortality [25]. Vegetables, and especially green leafy and beetroot, are the primary dietary nitrate source in our diet. Acute nitrate supplementation studies have been shown improved exercise performance, increasing walking distance [26-29], and lower blood pressure in COPD patients. Moreover, a daily vegetables rich diet showed better FEV1 (Forced Expiratory Volume in the 1st second), compared to a free choice diet [30]. Epidemiological studies highlighted a positive correlation between fruit and vegetable intake, COPD, and lung function [4,5,31-33]. In particular, a high intake of fruit and vegetables may protect the lungs from oxidative damage, through their antioxidant and anti-inflammatory properties, due to the high quantity of antioxidants, vitamins (particularly vitamin $\mathrm{C}, \mathrm{E}), \beta$-carotene, minerals, and fiber. In observational studies conducted in children adolescents, and middle-aged adults, circulating levels of other inflammatory mediators, such as tumor necrosis factor $\alpha$ (TNF $\alpha$ ), interleukin (IL-) 6, and IL-17A were inversely correlated with fruits and vegetable intake. A recent study reported that high vegetable intake, particularly green leafy and cruciferous vegetables, correlated with lower levels of white blood cell counts [34]. The anti-inflammatory effect of vegetable assumption could be explained considering their content in polyphenol compounds with antioxidant effect, folate, and flavonoids [35], and through their restoration of water loss and electrolyte balance function [36]. Moreover, the high dietary fiber content supports gut health and the growth of microbial species which potentially regulate the inhibition or production of pro-inflammatory chemokines and cytokines [37].

In a recent explorative study, we observed an association between daily diet and physical performance in a small group of 36 COPD patients undergoing pulmonary rehabilitation. Using the distance walked in six minutes (in meters) as the main outcome, we found a possible relationship between fruit and vegetable intake and the distance walked at the beginning of the rehabilitation program (135.71 \pm 74.6 for patients with low consumption versus $192.86 \pm 39.9$ in people with high consumption) (unpublished results). In the light of these data, we decided to further investigate the relationship between fruit and vegetable consumption and the rehabilitation response to underlie the related mechanisms. Thus, the objective of this study was to evaluate, based on high or low 
consumption of vegetables, the response of patients to pulmonary rehabilitation. Clinical parameters were integrated with cellular and molecular measurements to obtain a better and personalized treatment option for COPD patients.

\section{Results}

A total of 105 elderly patients (mean age \pm SD: $72,8 \pm 8,8$ years) were recruited with severe COPD at hospital admission after signing the informed consent. Patients were moderately overweight (mean BMI: 27.3), and were classified by the response to the treatment as non-responder or responder depending upon the distance gained after three weeks of rehabilitation. Demographic characteristics, lifestyle, and other clinical parameters are reported in Table 1 . There were no statistically significant differences in weight, height, BMI, years of education, education level, and marital status among responders and non-responders. No difference was also observed for smoking habits and fruit intake, while the vegetable intake was significantly higher in the group of responders $(p<0.05)$, and responders were significantly younger $(p<0.001)$. COPD patients did not respond differently to treatment depending on the number of comorbidities and oxygen therapy. Responders had a higher Barthel index at admission $(\mathrm{p}<0.001)$ and a better improvement at the end of rehabilitation $(\mathrm{p}<0.05)$ and started rehabilitation earlier than non-responders (6.0 vs 10.5 days; $\mathrm{p}<0.001)$.

Table 1. Baseline characteristics of COPD patients by response to the treatment

\begin{tabular}{|c|c|c|c|c|c|c|c|}
\hline Variable & $\mathbf{N}$ & $\begin{array}{l}\text { Total } \\
(105)\end{array}$ & $\mathbf{N}$ & $\begin{array}{c}\text { Non- } \\
\text { Responder } \\
\text { (36) }\end{array}$ & $\mathbf{N}$ & $\begin{array}{c}\text { Responder } \\
\text { (69) }\end{array}$ & $\begin{array}{c}\mathrm{p}- \\
\text { value }\end{array}$ \\
\hline Sex (male), No (\%) & 47 & 44.3 & 17 & 47.2 & 30 & 43.5 & NS \\
\hline Age-class, No (\%) & & & & & & & \\
\hline$\leq 66$ years & 25 & 23.8 & 4 & 11.1 & 21 & 30.4 & \\
\hline $67-73$ years & 28 & 26.7 & 3 & 8.3 & 25 & 36.2 & $<0.001$ \\
\hline $74-79$ years & 27 & 25.7 & 18 & 50.0 & 9 & 13.0 & \\
\hline$\geq 80$ years & 25 & 23.8 & 11 & 30.6 & 14 & 20.3 & \\
\hline Weight (Kg), mean (SD) & 75 & $72.5(21.8)$ & 16 & $73.7(23.6)$ & 59 & $72.1(21.5)$ & NS \\
\hline Height (cm), mean (SD) & 73 & $163.3(9.0)$ & 15 & $166.4(9.2)$ & 58 & $162.5(8.9)$ & NS \\
\hline BMI, mean (SD) & 72 & $27.3(7.8)$ & 14 & $25.8(8.3)$ & 58 & $27.7(7.7)$ & NS \\
\hline $\begin{array}{l}\text { Years of education, mean } \\
(\mathrm{SD})\end{array}$ & 105 & $9.0(4.0)$ & 36 & $9.3(4.5)$ & 69 & $9.0(3.7)$ & NS \\
\hline \multicolumn{8}{|l|}{$\begin{array}{l}\text { Years of education, No } \\
(\%)\end{array}$} \\
\hline 8 & 66 & 62.9 & 21 & 58.3 & 45 & 65.2 & NS \\
\hline $9-13$ & 32 & 30.5 & 11 & 30.6 & 21 & 30.4 & \\
\hline$>13$ & 7 & 6.7 & 4 & 11.1 & 3 & 4.3 & \\
\hline \multicolumn{8}{|l|}{ Marital Status, No (\%) } \\
\hline Unmarried & 6 & 5.7 & 4 & 11.1 & & $2(2.9)$ & \\
\hline Married & 55 & 52.4 & 23 & 63.9 & & $32(46.4)$ & NS \\
\hline Widow & 28 & 26.7 & 8 & 22.2 & & $20(29.0)$ & \\
\hline Divorced & 16 & 15.4 & 3 & 8.3 & & $13(18.8)$ & \\
\hline
\end{tabular}




\begin{tabular}{|c|c|c|c|c|c|c|c|}
\hline \multicolumn{8}{|l|}{ Smoking habit, No (\%) } \\
\hline Never & 12 & 12.8 & 4 & 13.8 & 8 & 12.3 & \\
\hline Former & 66 & 70.2 & 21 & 72.4 & 45 & 69.2 & NS \\
\hline Current & 16 & 17.0 & 4 & 13.8 & 12 & 18.5 & \\
\hline \multicolumn{8}{|l|}{ Fruit intake, No (\%) } \\
\hline High intake (daily) & 67 & 77.0 & 19 & 70.4 & 48 & 80.0 & NS \\
\hline $\begin{array}{c}\text { Low/Moderate intake } \\
\text { (weekly) }\end{array}$ & 20 & 23.0 & 8 & 29.6 & 12 & 20.0 & \\
\hline \multicolumn{8}{|l|}{ Vegetable intake, No (\%) } \\
\hline High intake (daily) & 46 & 57.5 & 10 & 40.0 & 36 & 65.4 & \\
\hline $\begin{array}{r}\text { Low/Moderate intake } \\
\text { (weekly) }\end{array}$ & 34 & 42.5 & 15 & 60.0 & 19 & 34.6 & 0.033 \\
\hline $\begin{array}{l}\Delta \text { from acute event (days), } \\
\text { median (IQR) }\end{array}$ & 105 & $8.0(9)$ & 36 & $10.5(12)$ & 69 & $6.0(7)$ & $0.001^{+}$ \\
\hline$\Delta 6 \mathrm{MWT}$, mean $(\mathrm{SD})$ & 105 & $93.1(84.1)$ & 36 & $1.14(4.7)$ & 69 & $137.4(61.0)$ & -- \\
\hline \multicolumn{8}{|l|}{$\begin{array}{l}\text { Barthel Index, median } \\
\text { (IQR) }\end{array}$} \\
\hline Hospital Admission & 105 & $76.0(40)$ & 36 & $42.0(33)$ & 69 & $83.0(13)$ & $<0.001^{+}$ \\
\hline Discharge & 103 & $91.0(20)$ & 34 & $66.0(26)$ & 69 & $95.0(9)$ & $<0.001^{+}$ \\
\hline$\Delta$ score & 103 & $14.0(9)$ & 34 & $23.5(21)$ & 69 & $14.0(11)$ & $0.033^{+}$ \\
\hline Oxigen therapy, No (\%) & 33 & 31.4 & 13 & 36.1 & 20 & 29.0 & NS \\
\hline $\begin{array}{l}\text { Number of } \\
\text { Comorbidities, mean (SD) }\end{array}$ & 105 & $3.42(1.71)$ & 36 & $3.86(1.99)$ & 69 & $3.13(1.45)$ & NS \\
\hline \multicolumn{8}{|l|}{$\begin{array}{l}\text { FEV1/FVC, No, mean } \\
(\mathrm{SD})\end{array}$} \\
\hline Admission & 52 & $47.3(24.3)$ & 8 & $31.6(20.8)$ & 44 & $50.1(24.0)$ & 0.085 \\
\hline Discharge & 32 & $61.7(22.7)$ & 4 & $58.1(17.0)$ & 28 & $62.2(23.6)$ & NS \\
\hline$\Delta$ score & 25 & $10.1(9.3)$ & 2 & $6.2(5.7)$ & 23 & $10.5(9.6)$ & NS \\
\hline
\end{tabular}

+Mann-Withney U-test

Table 2 shows changes in hematological parameters before and after pulmonary rehabilitation and the relative change $(\Delta)$ during this period. Patients with a better response to the rehabilitation have slightly more erythrocytes, and a higher hemoglobin concentration, especially at discharge $(12.7$ vs $11.3 \mathrm{~g} / \mathrm{dL}, \mathrm{p}<0.01)$. At the end of the rehabilitation program, also neutrophils and lymphocytes have different counts between the two groups. In particular, at discharge, responders had lower neutrophils counts $(p<0.05)$, and higher lymphocytes counts $(p<0.02)$ when compared to non-responders. Responders also showed also a significant difference in the variation of eosinophils during treatment (-0.3 vs $0.5, \mathrm{p}<0.01)$ No difference had found comparing responders and noresponders by the following tests: Blood Sugar, Azotemia, Total Bilirubin, $\mathrm{Na}+2, \mathrm{~K}+2$, ALT_GTP, AST_GTP, $\gamma \mathrm{GT}, \mathrm{pH}, \mathrm{pO}_{2}, \mathrm{pCO}_{2}, \mathrm{SpO}_{2}$, Heart Rate, Blood Pressure Systolic, Blood Pressure Diastolic (data not shown). 
Table 2. Characteristics of blood test parameters in COPD patients by the response to the treatment

\begin{tabular}{|c|c|c|c|c|c|c|c|}
\hline Variable & $\mathbf{N}$ & $\begin{array}{c}\text { Total } \\
\text { (n.105) }\end{array}$ & $\mathbf{N}$ & $\begin{array}{c}\text { Non- } \\
\text { Responder } \\
\text { (n.36) }\end{array}$ & $\mathbf{N}$ & $\begin{array}{l}\text { Responder } \\
\text { (n.69) }\end{array}$ & $\begin{array}{c}\text { p- } \\
\text { value }\end{array}$ \\
\hline \multicolumn{8}{|l|}{$\begin{array}{l}\text { Red Blood Cells, mean (SD) } \\
10^{\wedge} 6 / \mu L\end{array}$} \\
\hline Admission & 103 & $4.4(0.7)$ & 35 & $4.2(0.8)$ & 68 & $4.5(0.6)$ & 0.068 \\
\hline Discharge & 100 & $4.3(0.8)$ & 35 & $4.1(0.6)$ & 65 & $4.4(0.8)$ & 0.074 \\
\hline$\Delta$ score & 100 & $\begin{array}{c}-0.09 \\
(0.7)\end{array}$ & 35 & $-0.1(0.5)$ & 65 & $-0.08(0.7)$ & NS \\
\hline \multicolumn{8}{|l|}{ Platelets, mean (SD) $10^{\wedge} 3 / \mu L$} \\
\hline Admission & 102 & 245.3 & 34 & $242.2(90.1)$ & 68 & $246.8(89.2)$ & NS \\
\hline Discharge & 98 & $(89.1)$ & 34 & $219.5(89.3)$ & 64 & $198.4(71.4)$ & NS \\
\hline$\Delta$ score & 98 & $\begin{array}{l}205.7 \\
(78.3) \\
-39.3 \\
(78.3) \\
\end{array}$ & 34 & $-22.7(88.6)$ & 64 & $-48.1(71.3)$ & NS \\
\hline \multicolumn{8}{|l|}{$\begin{array}{l}\text { White Blood Cells, mean } \\
\text { number(SD) } 10^{\wedge} 3 / \mu L\end{array}$} \\
\hline Admission & 103 & $10.1(3.9)$ & 35 & $10.0(4.6)$ & 68 & $10.2(3.6)$ & NS \\
\hline Discharge & 99 & $9.8(3.3)$ & 35 & $10.0(3.9)$ & 64 & $9.7(3.0)$ & NS \\
\hline$\Delta$ score & 99 & $-0.4(3.6)$ & 35 & $-0.03(4.3)$ & 64 & $-0.5(3.2)$ & NS \\
\hline \multicolumn{8}{|l|}{$\begin{array}{l}\text { Neutrophils, mean number(SD) } \\
10^{\wedge} 3 / \mu L\end{array}$} \\
\hline Admission & 103 & 7.5 (72.9) & 35 & 7.7 (74.2) & 68 & $7.4(72.3)$ & NS \\
\hline Discharge & 99 & $6.9(68.5)$ & 35 & $7.6(72.6)$ & 64 & $6.5(66.3)$ & $0.025^{+}$ \\
\hline$\Delta$ score & 99 & $-0.7(4.7)$ & 35 & $-0.1(1.5)$ & 64 & $-0.1(6.4)$ & 0.056 \\
\hline \multicolumn{8}{|l|}{$\begin{array}{l}\text { Lymphocytes, mean } \\
\text { number(SD) } 10^{\wedge} 3 / \mu \mathrm{L}\end{array}$} \\
\hline Admission & 102 & $1.7(17.8)$ & 35 & 1.5 (16.7) & 67 & 1.8 (18.3) & NS \\
\hline Discharge & 99 & $2.0(21.9)$ & 35 & $1.6(18.5)$ & 64 & $2.2(23.7)$ & $0.016^{+}$ \\
\hline$\Delta$ score & 99 & $0.3(4.5)$ & 35 & $0.1(1.8)$ & 64 & $0.4(6.0)$ & 0.051 \\
\hline \multicolumn{8}{|l|}{$\begin{array}{l}\text { Monocytes, mean number(SD) } \\
10^{\wedge} 3 / \mu \mathrm{L}\end{array}$} \\
\hline Admission & 101 & $0.7(7.7)$ & 34 & $0.8(8.1)$ & 67 & $0.7(7.5)$ & NS \\
\hline Discharge & 99 & $0.6(7.6)$ & 35 & $0.6(7.6)$ & 64 & $0.6(7.6)$ & NS \\
\hline$\Delta$ score & 99 & $\begin{array}{l}-0.09 \\
(0.03)\end{array}$ & 34 & $-0.1(0.3)$ & 64 & $-0.08(0.2)$ & NS \\
\hline
\end{tabular}




\begin{tabular}{|c|c|c|c|c|c|c|c|}
\hline \multicolumn{8}{|l|}{$\begin{array}{l}\text { Eosinophils, mean number } \\
(S D) 10^{\wedge} 3 / \mu L\end{array}$} \\
\hline Admission & 101 & $0.1(1.2)$ & 34 & $0.10(1.6)$ & 67 & $0.09(1.1)$ & NS \\
\hline Discharge & 99 & $0.1(1.5)$ & 35 & $0.07(1.1)$ & 64 & 0.14 (1.6) & 0.087 \\
\hline$\Delta$ score & 97 & $0.02(0.2)$ & 34 & $-0.03(0.5)$ & 63 & $0.05(0.6)$ & 0.006 \\
\hline \multicolumn{8}{|l|}{$\begin{array}{l}\text { Basophils, mean number (SD) } \\
10^{\wedge} 3 / \mu L\end{array}$} \\
\hline Admission & 101 & $0.02(0.3)$ & 34 & $0.02(0.3)$ & 67 & $0.03(0.3)$ & NS \\
\hline Discharge & 99 & $0.03(0.3)$ & 35 & $0.03(0.4)$ & 64 & $0.03(0.3)$ & NS \\
\hline$\Delta$ score & 97 & $\begin{array}{l}0.004 \\
(0.04)\end{array}$ & 34 & $0.004(0.04)$ & 63 & $0.003(0.04)$ & NS \\
\hline \multicolumn{8}{|l|}{ Hemoglobin, mean (SD) g/dl } \\
\hline Admission & 66 & $12.6(1.8)$ & 21 & $12.0(1.9)$ & 45 & $12.9(1.8)$ & NS \\
\hline Discharge & 55 & $12.3(1.6)$ & 16 & $11.3(1.6)$ & 39 & $12.7(1.5)$ & 0.004 \\
\hline$\Delta$ score & 51 & $-0.5(2.1)$ & 15 & $-1.3(3.5)$ & 36 & $-0.2(1.1)$ & 0.093 \\
\hline
\end{tabular}

As regards biomarkers of oxidative stress, inflammation, and DNA damage COPD patients who positively responded to treatment showed a significantly lower VES at admission $(p<0.05)$, a difference that remained at the end of the three weeks of rehabilitation $(p<0.05)$. Responders who started rehabilitation with a lower level of inflammation (VES = 28.6) further reduced this parameter at discharge (VES = 23.9), while non-responders in the same period increased VES level, from 43.1 to 49.3 (Table 3). The apparent contrast with the $\Delta$ score reported in the table may be attributed to the smaller number of subjects with data on both admission and discharge. A similar pattern was shown by other biomarkers of oxidative stress and inflammation, with consistently higher values of IL-6, 8-OHdG, and MDA in the group of non-responders when compared to the group of responders (though only borderline significantly). A more evident difference between the two study groups concerned hematological markers of inflammation, with the group of responders showing at discharge a significantly higher lymphocytes/monocytes ratio $(\mathrm{p}<0.05)$, a lower neutrophils/lymphocytes ratio $(\mathrm{p}<0.05)$, and a lower platelets/lymphocytes ratio $(\mathrm{p}=0.01)$, all indexes featuring a lower level of inflammation. More uncertain, results of the comet assay with the two groups showed comparable levels of DNA damage.

Table 3. Biomarkers of oxidative stress, inflammation and DNA damage in COPD patients by response to the treatment

\begin{tabular}{|r|c|c|c|c|c|c|c|}
\hline \multicolumn{1}{|c|}{ Variable } & $\mathbf{N}$ & $\begin{array}{c}\text { Total } \\
\text { (n.105) }\end{array}$ & $\mathbf{N}$ & $\begin{array}{c}\text { Non- } \\
\text { Responder } \\
\text { (n.36) }\end{array}$ & $\mathbf{N}$ & $\begin{array}{c}\text { Responder } \\
\text { (n.69) }\end{array}$ & $\begin{array}{c}\text { p- } \\
\text { value }\end{array}$ \\
Admission & 97 & $33.2(28.0)$ & 31 & $43.1(32.7)$ & 66 & $28.6(24.4)$ & $\mathbf{0 . 0 2 4 ^ { + }}$ \\
Discharge & 68 & $31.0(30.6)$ & 19 & $49.3(39.2)$ & 49 & $23.9(23.3)$ & $\mathbf{0 . 0 1 3}$ \\
VEscore & 65 & $-5.5(27.2)$ & 18 & $-3.9(35.8)$ & 47 & $-6.1(23.5)$ & NS \\
\hline L-6, mean (SD) $\mathrm{mm} / \mathrm{h}$ & & & & & & \\
Admission & 73 & $66.6(107.9)$ & 20 & $90.3(116.5)$ & 53 & $57.6(104.2)$ & 0.054 \\
Discharge & 69 & $105.7(148.4)$ & 20 & $137.4(154.8)$ & 49 & $92.8(145.4)$ & 0.067 \\
\hline
\end{tabular}




\begin{tabular}{|c|c|c|c|c|c|c|c|}
\hline$\Delta$ score & 59 & $42.6(181.3)$ & 15 & 43.7 (196.6) & 44 & $42.3(178.1)$ & NS \\
\hline 8-OHdG, mean (SD) pg/ml & 38 & $24.7(8.1)$ & 13 & $25.6(8.9)$ & 25 & $24.2(7.9)$ & NS \\
\hline MDA, mean (SD) $\mu \mathrm{M}$ & 38 & $47.0(12.8)$ & 10 & $51.2(13.0)$ & 28 & $45.5(12.7)$ & NS \\
\hline \multicolumn{8}{|l|}{$\begin{array}{l}\text { Comet assay (Tail Intensity, } \\
\text { mean (SD)) }\end{array}$} \\
\hline Admission & 87 & $19.3(7.2)$ & 27 & $18.0(4.4)$ & 60 & $19.8(8.1)$ & NS \\
\hline Discharge & 86 & $22.0(7.3)$ & 26 & $21.9(8.2)$ & 60 & $22.0(6.9)$ & NS \\
\hline$\Delta$ score & 84 & $2.4(6.5)$ & 26 & $4.0(5.8)$ & 58 & $1.8(6.7)$ & NS \\
\hline \multicolumn{8}{|l|}{ Lymphocytes/Monocytes } \\
\hline Admission & 101 & 2.6 & 34 & 2.2 & 67 & 2.9 & NS \\
\hline Discharge & 99 & 3.3 & 35 & 2.7 & 64 & 3.6 & $0.040^{+}$ \\
\hline$\Delta$ score & 97 & 11.5 & 34 & 11.0 & 63 & 11.8 & NS \\
\hline \multicolumn{8}{|l|}{ Neutrophils/Lymphocytes } \\
\hline Admission & 102 & 5.5 & 34 & 6.1 & 67 & 5.2 & NS \\
\hline Discharge & 99 & 4.6 & 35 & 6.3 & 64 & 3.7 & $0.013^{+}$ \\
\hline$\Delta$ score & 98 & -1.2 & 35 & 3.8 & 63 & -4.1 & NS \\
\hline \multicolumn{8}{|l|}{ Platelets/Lymphocytes } \\
\hline Admission & 101 & 185.4 & 35 & 207.7 & 67 & 174.1 & NS \\
\hline Discharge & 98 & 135.6 & 35 & 178.2 & 64 & 113.1 & $0.010^{+}$ \\
\hline$\Delta$ score & 97 & -48.1 & 35 & -48.6 & 63 & -47.8 & NS \\
\hline
\end{tabular}

In table 4 is reported a parallel analysis comparing the level of oxidative stress, inflammation, and DNA damage in COPD patients by vegetable intake. A comprehensive evaluation of all biomarkers showed as subjects with lower daily consumption of vegetables had a higher level of oxidation, although in some cases statistical significance could not be achieved. The ratio of Lymphocytes/Monocytes $(\mathrm{p}<0.01)$, Neutrophils/Lymphocytes $(\mathrm{p}<0.02)$, and Platelets/Lymphocytes (though supported by a borderline statistic $(\mathrm{p}=0.07)$ ) showed consistently higher levels of inflammation in patients with a lower intake of vegetables. Other markers of inflammation showed similar results, although only IL-6 levels at the end of rehabilitation reached a nearly significant performance $(p=0.05)$. The amount of oxidative stress, measured with the malondialdehyde assay, was higher in patients with a lower vegetable intake $(\mathrm{p}<0.066)$, while the genomic instability measured with 8-OHdG and with the alkaline comet assay did not show significant differences, although a borderline significant increase of DNA damage was observed during treatment in patients with a lower intake of vegetables. 
Table 4. Biomarkers of oxidative stress, inflammation and DNA damage in COPD patients by daily vegetables intake

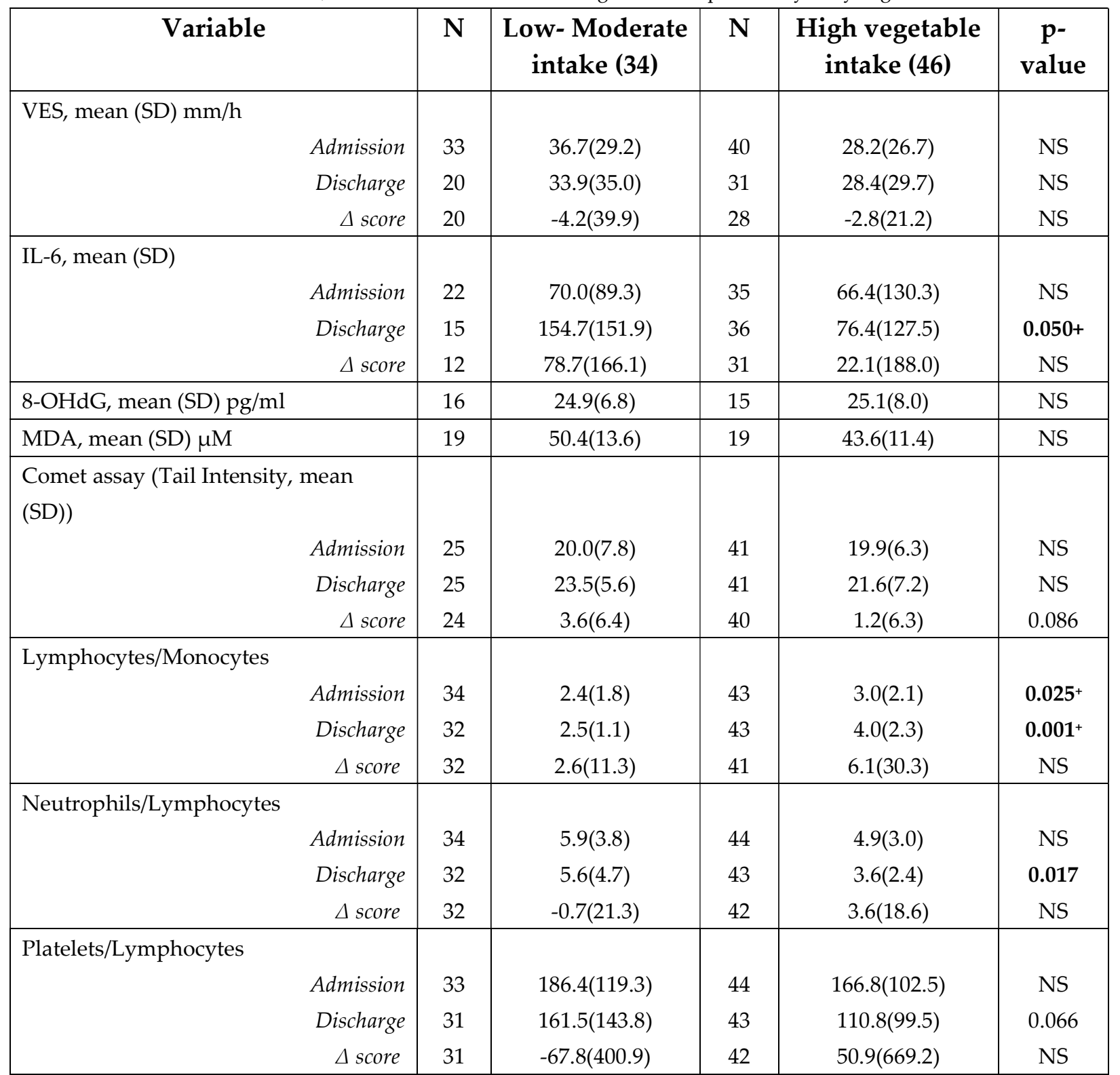

\section{Discussion}

The results of this study showed a marked improvement in most clinical and functional parameters of COPD patients after three weeks of PR. Our results, in line with literature, showed that high vegetable intake regularly assumed with normal diet, without any specific intervention, could make a difference in the response to rehabilitation therapy, even in patients affected by severe COPD.

Considerable evidence determined the crucial role of oxidative stress and associated inflammation in COPD patients; indeed, if compared to healthy subjects, COPD patients had a significant increase in markers of oxidative stress and ROS-induced DNA damage $[4,5]$. Specifically, oxidative stress occurs when free radicals (reactive oxygen and nitrogen species) exceed the availability of antioxidants, thus causing pathological reactions responsible for numerous diseases, including respiratory ones, and in particular, COPD. 
Elevated ROS production is directly responsible for increased in lipid peroxidation products (MDA), DNA damage, and the onset of inflammation. The interplay between oxidative stress, oxidative DNA damage, and inflammation, how these events are associated with the success of rehabilitation, and the role of dietary intake of antioxidants is summarized in Figure 1 and is the aim of this study.

The prolonged inflammatory status, induced by the chronic low-grade inflammation, plays a critical role in COPD, inducing irreparable damage to tissues and organs, increasing the risk of disease, and favoring its progression. IL-6, a product of the ongoing inflammation in the airways, is a key modulator of the overall immune response and nonimmune cells function [38]. This cytokine can modify the cellular apoptotic response since when cells are exposed to oxidizing agents, elevated levels of IL-6 block proapoptotic pathways (via blc2 or mlc-1) and also promote cell proliferation [39]. Lymphocytes/monocytes ratio (LMR), neutrophils/lymphocytes ratio (NLR), and platelet/lymphocytes ratio (PLR) are rather novel inflammatory markers. They have gained enormous reliability in many chronic inflammatory diseases, starting from the first description of NLR increase in cancer patients in 2001 [40] and, interestingly, represent a good marker of exercise-induced inflammation [41]. Taken all data together, seems that oxidative stress can initiate the inflammatory process, and through the modification of lipids, proteins, and nucleic acids, it can also maintain the disease state by creating a vicious circle (Figure 2).

Evidence emphasizes the importance of diet as a modifiable risk factor for COPD and that some adverse functional consequences of severe COPD are reversible by nutritional support [5]. A recent study suggested that a dietary nitrate supplementation can improve the effect of pulmonary rehabilitation [29]. Moreover, according to different systemic reviews, meta-analysis of prospective cohort and cross-sectional studies, and other analysis and reviews of the dietary intervention studies on COPD patients [42,43], it has been suggested that there is inverse and independent association between high long-term consumption of fruits (in both men and women) and vegetables (only in men) and 35\% lower risk of COPD incidence in men, and 37\% lower risk in women [42,43]. Consistent evidence has also been reported also for DNA damage and genomic instability [9].

The results of the present study, confirmed to a great extent the model featured in Figure 1, even if in some cases with-out the support of statistical significance for the relatively small number of patients. For the sake of simplicity, patients admitted to rehabilitation were classified as responders or non-responders according to the presence of a clinically significant improvement in the number of meters walked in 6 minutes, a generally accepted and comprehensive index of rehabilitation performance. The presence of an improved effect of rehabilitation in patients reporting a high intake of vegetables, observed in a pilot study on COPD patients (unpublished results), was confirmed by the results reported in Table 1, where the vegetable intake was the only significant predictor of response besides age and days from the acute event. However, the strength of this study is the evaluation of several steps of the pathway linking diet to rehabilitation performance.

The intake of antioxidants, through a diet rich in vegetables, had a beneficial effect on the mechanisms described in Figure 2, intervening in DNA metabolism and DNA repair, helping to maintain the stability of the genome, and fighting the effects of oxidative stress. Hematological markers of inflammation LMR and NLR showed a strong and significant difference by the intensity of response to treatment, while VES, IL-6, MDA, and the comet assay although showing no or borderline significant difference were consistent in reporting higher indexes of damage in subjects with a lower response.

Surprisingly, the ROS-induced DNA damage, measured with $8 \mathrm{OHdG}$ and partially with the alkaline comet assay, in COPD patients, either before or after three weeks of pulmonary rehabilitation, failed to show major differences associated with dietary intake of vegetable or response to rehabilitation (finding already reported by Russo et al 2019 [19]). Furthermore, Mercken et al. in 2005 [12], also showed that COPD patients at eight weeks of rehabilitation had no significant increases in ROS-induced DNA damage, unlike 
what occurred immediately after peak exercise. These data are comparable with the variation in oxidative stress, measured by MDA assay in the plasma of COPD responder and non-responder patients during rehabilitation. Indeed, even in this case, we did not observe any significant variation in MDA levels between responders and non-responders, either before or after rehabilitation treatment. A possible explanation of these findings is that patients who received three weeks of pulmonary rehabilitation probably have not yet reached a sufficient training state to counteract the values of DNA damage and oxidative stress induced by ROS.

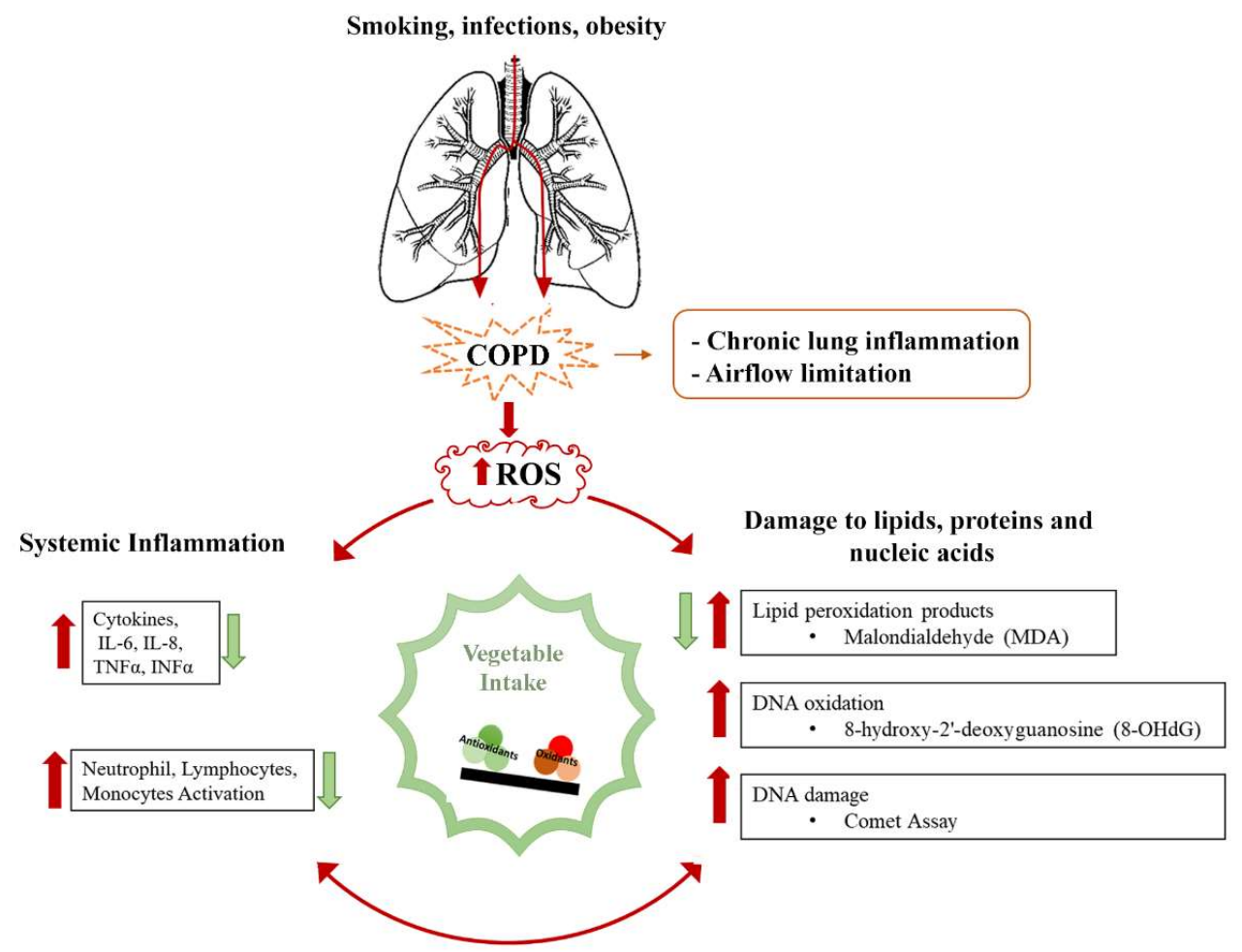

Figure 2: Scheme summarizing this study. Continued production of ROS, due to increased oxidative stress, systemic inflammation, and DNA damage, is responsible for the development and maintenance of severe COPD. This mechanism is attenuated following the pulmonary rehabilitation program and through a high vegetable intake.

From a comprehensive reading of these data, there is evidence that COPD patients with high vegetable intake had a slight reduction in MDA levels and DNA damage, and a more remarkable decrease in inflammatory status, as confirmed by the decrease of blood parameters NLR and LMR. This observation is also crucial for the prevention of COPD exacerbations, given that it has been shown that high NLR $(>3.54)$ is a strong predictor of the risk of developing exacerbations [44]. Therefore, it can be speculated that a high vegetable intake could also help in the prevention of exacerbation in COPD patients.

In recent years, the control of inflammation and DNA damage-associated oxidative stress, together with nutrients intake (as an important part of non-pharmacological strategies, usually with/without physical exercise included), is gaining more and more attention for their possible role in strategies to prevent exacerbations and contrast disease progression. Currently, the standard of care is mostly based on pharmacological interventions, including short-acting bronchodilator drugs (prescribed to patients for immediate relief) and long-acting muscarine receptor antagonists, beta-2 agonists, or corticosteroids [45]. The difference in the vegetable intake between responders and nonresponders, together with the general improvement in inflammatory levels among COPD 
patients with high consumption of vegetables and after three weeks of rehabilitation treatment, raises the point of a future consideration of these parameters in the prevention and rehabilitation of COPD patients.

The present study has several strengths. The most remarkable is the observed consistency between biomarkers findings and the candidate mechanism, based on the results of the preliminary study and on published evidence. Among the weaknesses, small numbers are the most restrictive. The reference group in our study reported a moderate (weekly) intake of vegetables (only one subject in the whole study group reported eating vegetable less than once per week). The use of a control group with a non-minimal consumption of vegetables, while has reproduced a real-life condition, has probably underestimated the anti-inflammatory effect of this diet.

In conclusion, this study demonstrated that high vegetable intake, without any specific intervention, can identify COPD patients with a higher probability to respond successfully to rehabilitation. In addition, while 3 weeks of pulmonary rehabilitation are probably too short to reveal an improvement in oxidative stress and DNA damage, they are still sufficient for an improvement in the patient's inflammatory state in responder vs non-responder patients, or by high or moderate vegetable intake.

\section{Materials and Methods}

Study design and participants

A cross-sectional study was carried out in 105 patients aged 70 years or older suffering from severe COPD and admitted to the Pulmonary Rehabilitation (PR) Unit of the IRCCS San Raffaele Pisana between January 2013 and December 2015 for a comprehensive 3 weeks PR program. Peripheral blood samples were collected and stored at $-80^{\circ} \mathrm{C}$ at admission and after 3 weeks of PR. Additional detail of the study population can be found in Russo et al., (2019) [19]. The study was approved by the ethics committee of the IRCCS San Raffaele Pisana (Prot. 15/2013), and all participants signed the consent to participate in the study at admission.

\section{Rehabilitation}

All patients received daily inhalation treatment with corticosteroids (beclomethasone dipropionate $\left[\mathrm{C}_{28} \mathrm{H}_{37} \mathrm{ClO}_{7}\right](0.4 \mathrm{mg} / \mathrm{ml})$, in combination with bronchodilators, i.e., SABA (Short Acting Beta2 Agonists in our patients Salbutamol) and SAMA (Short-Acting Muscarinic Antagonist in our patients' anti sub type M3: Ipratropium bromide) for 3 weeks. A questionnaire was administered at admission with questions about demographics, medical history, life-style, including a frequency intake of selected food items. Anthropometric measures, cognitive function, and the long-term use of oxygen therapy were recorded as well. An instrumental evaluation of spirometry, pulse oximetry, blood pressure, electrocardiography (ECG), heart beats, the disease-specific respiratory status (Medical Research Council, MRC), the Barthel and the Borg scales for assessing dyspnea, and the functional exercise capacity (six Minutes Walking Test (6MWT)), was assessed at baseline and at discharge. The choice of the 6MWT distance threshold, indicating an actual response to treatment is still under debate. Nevertheless, the distance of $\geq 30 \mathrm{~m}$ especially in advanced COPD patients, has been indicated by many as a clinically significant response [46].

\section{Alkaline Comet assay}

The complete detailed procedure for the assay can be found in our previous work [19]. In summary, following new guidelines for minimal required detailed information on reporting comet assay procedure [47] and new technical recommendations [48,49], DNA damage of lymphocytes embedded in agarose was analyzed after lysation, denaturation, electrophoresis and staining with the Comet assay IV software (Instem, London, Uk). Tail 
intensity values (TI, \% DNA in comet tail) were calculated from 100 comets counted for each individual.

Markers of oxidative stress

The following markers of oxidative stress were measured to evaluate the difference associated with vegetable consumption or response to treatment.

Malonaldehyde (MDA) Assay

MDA quantification was performed through thiobarbituric acid reactive substances (TBARS) assay in plasma. Briefly, plasma samples were transferred to a vial containing $10 \% \mathrm{NaOH}, 20 \%$ Acetic Acid and TBA. Vials were boiled at $95{ }^{\circ} \mathrm{C}$ for $1 \mathrm{~h}$, and then were placed on ice to stop the reaction. Samples were centrifugated $10 \mathrm{~min}$ at $1600 \times \mathrm{g}$ at $4{ }^{\circ} \mathrm{C}$ and then were placed in a black 96-well microtiter plate. MDA-TBA adduct was measured spectrophotometrically at $530 \mathrm{~nm}$ using Tecan sunrise (Tecan).

8-hydroxy-2'-deoxyguanosine (8OHdG) Assay

8-hydroxy-2'-deoxyguanosine (8OHdG) was performed using an immunecompetitive assay (8-hydroxydeoxyguanosine (8-OHdG), Biomatik ELISA kit, Biomatik) in plasma, following the manufacturer's protocol. The absorbance was measured at 450 $\mathrm{nm}$ using tecan sunrise (Tecan). The values obtained were expressed as $\mathrm{pg} / \mathrm{ml}$.

\section{Markers of inflammation \\ IL-6 quantification}

Interleukin 6 (IL-6) levels were determined by Enzyme-Linked Immunosorbent Assay (ELISA) in plasma, following the manufacturer's protocols, using the Human IL-6 DuoSet ELISA (R\&D Systems, Minneapolis, MN).

\section{Blood Test}

The number and percentage of peripheral blood cells were evaluated during routine laboratory analysis using standard blood count automated methods (Beckman Coulter LH500). LMR, NLR PLR were calculated for each patient diving the absolute cell numbers of the indicated subpopulation, taken from complete blood count. Subsequently, the mean and standard deviation for observed values has been calculated. An increase in NLR and in PLR, as well as a decrease in LMR are indicative of an ongoing inflammation. (Ye Z, Medicine (Baltimore). 2019; 98 (28): e16371; Gu L. Oncotarget. 2016; 7 (22), 31926-42. Zhou X PLoS One. 2014; 9 (6), e101119.)

\section{Statistical Methods}

Descriptive statistics of epidemiological, clinical, and biological data were represented as the frequency with percentage, mean with standard deviation for categorical and continuous variables, respectively. Group differences in demographic, clinical, and laboratory data were assessed using the Student's $t$-test or the Mann-Whitney $U$ test depending upon the distribution of variables. For the comparison of qualitative variables, the $\chi^{2}$ test was used. A statistically significant value was considered $p \leq 0.05$. All statistical analyses were done using the statistical software SPSS, version 26.0.

Author Contributions: Conceptualization and supervision, S.B, and P.R.; methodology, M.M.; validation, C.M., C.T. B.G.; investigation, V.C.; data curation, S.P.; writing-original draft preparation, S.I. and L.V. All authors have read and agreed to the published version of the manuscript. Please turn to the CRediT taxonomy for the term explanation.

Funding: The study was supported by funds granted by the Italian Ministry of Health for Institutional Research (Ricerca Corrente). 
Institutional Review Board Statement: The study was conducted according to the guidelines of the Declaration of Helsinki and approved by the Ethics Committee The study was approved by the ethics committee of the IRCCS San Raffaele Pisana (Prot. 15/2013).

Informed Consent Statement: Informed consent was obtained from all subjects involved in the study.

Data Availability Statement: The data presented in this study are available on request from the corresponding author. The data are not publicly available due to privacy restrictions from the ethics committee.

Acknowledgments: none

Conflicts of Interest: The authors declare no conflict of interest.

\section{References}

1. Zinellu, E.; Zinellu, A.; Fois, A.G.; Fois, S.S.; Piras, B.; Carru, C.; Pirina, P. Reliability and Usefulness of Different Biomarkers of Oxidative Stress in Chronic Obstructive Pulmonary Disease. Oxid Med Cell Longev 2020, 2020, 4982324, doi:10.1155/2020/4982324.

2. Lee, S. COPD, 1 ed.; SD, L., Ed. 2017; 10.1007/978-3-662-47178-4.

3. Bales CW, L.J., Saltzman E. Handbook of Clinical Nutrition and Aging, Third edition ed.; Bales, C.W., Locher, J.L., Saltzman, E., Eds.; Humana Press: 2009; 10.1007/978-1-4939-1929-1pp. XXVII, 442.

4. Zhai, H.; Wang, Y.; Jiang, W. Fruit and Vegetable Intake and the Risk of Chronic Obstructive Pulmonary Disease: A Dose-Response Meta-Analysis of Observational Studies. Biomed Res Int 2020, 2020, 3783481, doi:10.1155/2020/3783481.

5. Scoditti, E.; Massaro, M.; Garbarino, S.; Toraldo, D.M. Role of Diet in Chronic Obstructive Pulmonary Disease Prevention and Treatment. Nutrients 2019, 11, doi:10.3390/nu11061357.

6. Neofytou, E.; Tzortzaki, E.G.; Chatziantoniou, A.; Siafakas, N.M. DNA damage due to oxidative stress in Chronic Obstructive Pulmonary Disease (COPD). Int J Mol Sci 2012, 13, 16853-16864, doi:10.3390/ijms131216853.

7. Chamitava, L.; Cazzoletti, L.; Ferrari, M.; Garcia-Larsen, V.; Jalil, A.; Degan, P.; Fois, A.G.; Zinellu, E.; Fois, S.S.; Fratta Pasini, A.M., et al. Biomarkers of Oxidative Stress and Inflammation in Chronic Airway Diseases. Int J Mol Sci 2020, 21, doi:10.3390/ijms21124339.

8. Ilari, S.; Giancotti, L.A.; Lauro, F.; Dagostino, C.; Gliozzi, M.; Malafoglia, V.; Sansone, L.; Palma, E.; Tafani, M.; Russo, M.A., et al. Antioxidant modulation of sirtuin 3 during acute inflammatory pain: The ROS control. Pharmacol Res 2020, 157, 104851, doi:10.1016/j.phrs.2020.104851.

9. Asanov, M.; Bonassi, S.; Proietti, S.; Minina, V.I.; Tomino, C.; R.El-Zein. Genomic instability in chronic obstructive pulmonary disease and lung cancer: A systematic review and meta-analysis of studies using the micronucleus assay. Mutation Research/Reviews in Mutation Research 2021, 787, 108344, doi:https://doi.org/10.1016/j.mrrev.2020.108344.

10. Chen, H.; Wang, Y.; Bai, C.; Wang, X. Alterations of plasma inflammatory biomarkers in the healthy and chronic obstructive pulmonary disease patients with or without acute exacerbation. J Proteomics 2012, 75, 2835-2843, doi:10.1016/j.jprot.2012.01.027.

11. Schols, A.M.; Buurman, W.A.; Staal van den Brekel, A.J.; Dentener, M.A.; Wouters, E.F. Evidence for a relation between metabolic derangements and increased levels of inflammatory mediators in a subgroup of patients with chronic obstructive pulmonary disease. Thorax 1996, 51, 819-824, doi:10.1136/thx.51.8.819.

12. Mercken, E.M.; Hageman, G.J.; Schols, A.M.; Akkermans, M.A.; Bast, A.; Wouters, E.F. Rehabilitation decreases exercise-induced oxidative stress in chronic obstructive pulmonary disease. Am J Respir Crit Care Med 2005, 172, 994-1001, doi:10.1164/rccm.200411-1580OC. 
13. Wedzicha, J.A.; Donaldson, G.C. Exacerbations of chronic obstructive pulmonary disease. Respir Care 2003, 48, 1204-1213; discussion 1213-1205.

14. Chung, K.F.; Adcock, I.M. Multifaceted mechanisms in COPD: inflammation, immunity, and tissue repair and destruction. Eur Respir J 2008, 31, 1334-1356, doi:10.1183/09031936.00018908.

15. Spruit, M.A.; Singh, S.J.; Garvey, C.; ZuWallack, R.; Nici, L.; Rochester, C.; Hill, K.; Holland, A.E.; Lareau, S.C.; Man, W.D., et al. An official American Thoracic Society/European Respiratory Society statement: key concepts and advances in pulmonary rehabilitation. Am J Respir Crit Care Med 2013, 188, e13-64, doi:10.1164/rccm.2013091634ST.

16. Rochester, C.L.; Vogiatzis, I.; Holland, A.E.; Lareau, S.C.; Marciniuk, D.D.; Puhan, M.A.; Spruit, M.A.; Masefield, S.; Casaburi, R.; Clini, E.M., et al. An Official American Thoracic Society/European Respiratory Society Policy Statement: Enhancing Implementation, Use, and Delivery of Pulmonary Rehabilitation. Am J Respir Crit Care Med 2015, 192, 1373-1386, doi:10.1164/rccm.201510-1966ST.

17. Simioni, C.; Zauli, G.; Martelli, A.M.; Vitale, M.; Sacchetti, G.; Gonelli, A.; Neri, L.M. Oxidative stress: role of physical exercise and antioxidant nutraceuticals in adulthood and aging. Oncotarget 2018, 9, 17181-17198, doi:10.18632/oncotarget.24729.

18. Ilari, S.; Giancotti, L.A.; Lauro, F.; Gliozzi, M.; Malafoglia, V.; Palma, E.; Tafani, M.; Russo, M.A.; Tomino, C.; Fini, M., et al. Natural Antioxidant Control of Neuropathic Pain-Exploring the Role of Mitochondrial SIRT3 Pathway. Antioxidants (Basel) 2020, 9, doi:10.3390/antiox9111103.

19. Russo, P.; Lamonaca, P.; Milic, M.; Rojas, E.; Prinzi, G.; Cardaci, V.; Vitiello, L.; Proietti, S.; Santoro, A.; Tomino, C., et al. Biomarkers of DNA damage in COPD patients undergoing pulmonary rehabilitation: Integrating clinical parameters with genomic profiling. Mutat Res 2019, 843, 111-117, doi:10.1016/j.mrgentox.2019.04.003.

20. Fenech, M.; Knasmueller, S.; Bolognesi, C.; Holland, N.; Bonassi, S.; Kirsch-Volders, M. Micronuclei as biomarkers of DNA damage, aneuploidy, inducers of chromosomal hypermutation and as sources of proinflammatory DNA in humans. Mutat Res 2020, 786, 108342, doi:10.1016/j.mrrev.2020.108342.

21. Pittaluga, M.; Sgadari, A.; Dimauro, I.; Tavazzi, B.; Parisi, P.; Caporossi, D. Physical exercise and redox balance in type 2 diabetics: effects of moderate training on biomarkers of oxidative stress and DNA damage evaluated through comet assay. Oxid Med Cell Longev 2015, 2015, 981242, doi:10.1155/2015/981242.

22. Kaluza, J.; Larsson, S.C.; Orsini, N.; Linden, A.; Wolk, A. Fruit and vegetable consumption and risk of COPD: a prospective cohort study of men. Thorax 2017, 72, 500-509, doi:10.1136/thoraxjnl-2015-207851.

23. Varraso, R.; Chiuve, S.E.; Fung, T.T.; Barr, R.G.; Hu, F.B.; Willett, W.C.; Camargo, C.A. Alternate Healthy Eating Index 2010 and risk of chronic obstructive pulmonary disease among US women and men: prospective study. BMJ 2015, 350, h286, doi:10.1136/bmj.h286.

24. Butler, T.; Kerley, C.P.; Altieri, N.; Alvarez, J.; Green, J.; Hinchliffe, J.; Stanford, D.; Paterson, K. Optimum nutritional strategies for cardiovascular disease prevention and rehabilitation (BACPR). Heart 2020, 106, 724731, doi:10.1136/heartjnl-2019-315499.

25. Woolcott, C.G.; Dishman, R.K.; Motl, R.W.; Matthai, C.H.; Nigg, C.R. Physical activity and fruit and vegetable intake: correlations between and within adults in a longitudinal multiethnic cohort. Am J Health Promot 2013, 28, 71-79, doi:10.4278/ajhp.100917-QUAN-312.

26. Berry, M.J.; Justus, N.W.; Hauser, J.I.; Case, A.H.; Helms, C.C.; Basu, S.; Rogers, Z.; Lewis, M.T.; Miller, G.D. Dietary nitrate supplementation improves exercise performance and decreases blood pressure in COPD patients. Nitric Oxide 2015, 48, 22-30, doi:10.1016/j.niox.2014.10.007. 
27. Leong, P.; Basham, J.E.; Yong, T.; Chazan, A.; Finlay, P.; Barnes, S.; Bardin, P.G.; Campbell, D. A double blind randomized placebo control crossover trial on the effect of dietary nitrate supplementation on exercise tolerance in stable moderate chronic obstructive pulmonary disease. BMC Pulm Med 2015, 15, 52, doi:10.1186/s12890-0150057-4.

28. Kerley, C.P.; James, P.E.; McGowan, A.; Faul, J.; Cormican, L. Dietary nitrate improved exercise capacity in COPD but not blood pressure or pulmonary function: a 2 week, double-blind randomised, placebo-controlled crossover trial. Int J Food Sci Nutr 2019, 70, 222-231, doi:10.1080/09637486.2018.1492521.

29. Pavitt, M.J.; Tanner, R.J.; Lewis, A.; Buttery, S.; Mehta, B.; Jefford, H.; Curtis, K.J.; Banya, W.A.S.; Husain, S.; Satkunam, K., et al. Oral nitrate supplementation to enhance pulmonary rehabilitation in COPD: ON-EPIC a multicentre, double-blind, placebo-controlled, randomised parallel group study. Thorax 2020, 75, 547-555, doi:10.1136/thoraxjnl-2019-214278.

30. Keranis, E.; Makris, D.; Rodopoulou, P.; Martinou, H.; Papamakarios, G.; Daniil, Z.; Zintzaras, E.; Gourgoulianis, K.I. Impact of dietary shift to higher-antioxidant foods in COPD: a randomised trial. Eur Respir J 2010, 36, 774780, doi:10.1183/09031936.00113809.

31. Domej, W.; Oettl, K.; Renner, W. Oxidative stress and free radicals in COPD--implications and relevance for treatment. Int J Chron Obstruct Pulmon Dis 2014, 9, 1207-1224, doi:10.2147/COPD.S51226.

32. Russo, P.; Prinzi, G.; Lamonaca, P.; Cardaci, V.; Fini, M. Flavonoids and Reduction of Cardiovascular Disease (CVD) in Chronic Obstructive Pulmonary Disease (COPD). Curr Med Chem 2019, 26, 7048-7058, doi:10.2174/0929867325666180514100640.

33. Seyedrezazadeh, E.; Moghaddam, M.P.; Ansarin, K.; Asghari Jafarabadi, M.; Sharifi, A.; Sharma, S.; Kolahdooz, F. Dietary Factors and Risk of Chronic Obstructive Pulmonary Disease: a Systemic Review and Meta-Analysis. Tanaffos 2019, 18, 294-309.

34. Menni, C.; Louca, P.; Berry, S.E.; Vijay, A.; Astbury, S.; Leeming, E.R.; Gibson, R.; Asnicar, F.; Piccinno, G.; Wolf, J., et al. High intake of vegetables is linked to lower white blood cell profile and the effect is mediated by the gut microbiome. BMC Med 2021, 19, 37, doi:10.1186/s12916-021-01913-w.

35. Zern, T.L.; Wood, R.J.; Greene, C.; West, K.L.; Liu, Y.; Aggarwal, D.; Shachter, N.S.; Fernandez, M.L. Grape polyphenols exert a cardioprotective effect in pre- and postmenopausal women by lowering plasma lipids and reducing oxidative stress. J Nutr 2005, 135, 1911-1917, doi:10.1093/jn/135.8.1911.

36. Wu, T.; Shinde, R.; Castro, R.; Pierce, J.P. Interrelationship of Seasons with Inflammation, Red Meat, Fruit, and Vegetable Intakes, Cardio-Metabolic Health, and Smoking Status among Breast Cancer Survivors. J Clin Med 2021, 10, doi:10.3390/jcm10040636.

37. Davis, R.; Day, A.; Barrett, J.; Vanlint, A.; Andrews, J.M.; Costello, S.P.; Bryant, R.V. Habitual dietary fibre and prebiotic intake is inadequate in patients with inflammatory bowel disease: findings from a multicentre crosssectional study. J Hum Nutr Diet 2021, 34, 420-428, doi:10.1111/jhn.12812.

38. Rincon, M.; Irvin, C.G. Role of IL-6 in asthma and other inflammatory pulmonary diseases. Int J Biol Sci 2012, 8, 1281-1290, doi:10.7150/ijbs.4874.

39. Chen, Y.; Zhang, F.; Tsai, Y.; Yang, X.; Yang, L.; Duan, S.; Wang, X.; Keng, P.; Lee, S.O. IL-6 signaling promotes DNA repair and prevents apoptosis in CD133+ stem-like cells of lung cancer after radiation. Radiat Oncol 2015, 10, 227, doi:10.1186/s13014-015-0534-1.

40. Zahorec, R. Ratio of neutrophil to lymphocyte counts--rapid and simple parameter of systemic inflammation and stress in critically ill. Bratisl Lek Listy 2001, 102, 5-14. 
41. Walzik, D.; Joisten, N.; Zacher, J.; Zimmer, P. Transferring clinically established immune inflammation markers into exercise physiology: focus on neutrophil-to-lymphocyte ratio, platelet-to-lymphocyte ratio and systemic immune-inflammation index. Eur J Appl Physiol 2021, 10.1007/s00421-021-04668-7, doi:10.1007/s00421-02104668-7.

42. Salari-Moghaddam, A.; Milajerdi, A.; Larijani, B.; Esmaillzadeh, A. Processed red meat intake and risk of COPD: A systematic review and dose-response meta-analysis of prospective cohort studies. Clin Nutr 2019, 38, 11091116, doi:10.1016/j.clnu.2018.05.020.

43. Parvizian, M.K.; Dhaliwal, M.; Li, J.; Satia, I.; Kurmi, O.P. Relationship between dietary patterns and COPD: a systematic review and meta-analysis. ERJ Open Res 2020, 6, doi:10.1183/23120541.00168-2019.

44. Acarturk Tuncay, E.; Karakurt, Z.; Aksoy, E.; Salturk, C.; Gungor, S.; Ciftaslan, N.; Irmak, I.; Yavuz, D.; Ocakli, B.; Adiguzel, N. Eosinophilic and non-eosinophilic COPD patients with chronic respiratory failure: neutrophilto-lymphocyte ratio as an exacerbation marker. Int J Chron Obstruct Pulmon Dis 2017, 12, 3361-3370, doi:10.2147/COPD.S147261.

45. Bhatta, L.; Leivseth, L.; Mai, X.M.; Henriksen, A.H.; Carslake, D.; Chen, Y.; Langhammer, A.; Brumpton, B.M. GOLD Classifications, COPD Hospitalization, and All-Cause Mortality in Chronic Obstructive Pulmonary Disease: The HUNT Study. Int J Chron Obstruct Pulmon Dis 2020, 15, 225-233, doi:10.2147/COPD.S228958.

46. Holland, A.E.; Spruit, M.A.; Troosters, T.; Puhan, M.A.; Pepin, V.; Saey, D.; McCormack, M.C.; Carlin, B.W.; Sciurba, F.C.; Pitta, F., et al. An official European Respiratory Society/American Thoracic Society technical standard: field walking tests in chronic respiratory disease. Eur Respir J 2014, 44, 1428-1446, doi:10.1183/09031936.00150314.

47. Moller, P.; Azqueta, A.; Boutet-Robinet, E.; Koppen, G.; Bonassi, S.; Milic, M.; Gajski, G.; Costa, S.; Teixeira, J.P.; Costa Pereira, C., et al. Minimum Information for Reporting on the Comet Assay (MIRCA): recommendations for describing comet assay procedures and results. Nat Protoc 2020, 15, 3817-3826, doi:10.1038/s41596-020-03981 .

48. Azqueta, A.; Ladeira, C.; Giovannelli, L.; Boutet-Robinet, E.; Bonassi, S.; Neri, M.; Gajski, G.; Duthie, S.; Del Bo, C.; Riso, P., et al. Application of the comet assay in human biomonitoring: An hCOMET perspective. Mutat Res 2020, 783, 108288, doi:10.1016/j.mrrev.2019.108288.

49. Milic, M.; Ceppi, M.; Bruzzone, M.; Azqueta, A.; Brunborg, G.; Godschalk, R.; Koppen, G.; Langie, S.; Møller, P.; Teixeira, J.P., et al. The hCOMET project: International database comparison of results with the comet assay in human biomonitoring. Baseline frequency of DNA damage and effect of main confounders. Mutat Res 2021, 787, 108371, doi:https://doi.org/10.1016/j.mrrev.2021.108371. 